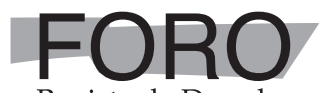

Revista de Derecho

\title{
El matrimonio igualitario a la luz de la Convención Americana: análisis de la Opinión Consultiva OC-24/17 en el contexto jurídico ecuatoriano
}

Equal marriage in the light of the American Convention: Analysis of the Advisory Opinion OC-24/17 in the Ecuadorian legal framework

Gissela Cristina Paredes Erazo

Universidad de Valencia, España gissela.paredese@funcionjudicial.gob.ec ORCID: 0000-0003-3861-3059

\section{María Dolores Núñez Ávila}

Universidad de Valencia, España

madonua@alumni.uv.es

ORCID: 0000-0002-4705-8002

DOI: https://doi.org/10.32719/26312484.2019.32.4

Fecha de recepción: 30 de abril de 2019

Fecha de aceptación: 19 de julio de 2019

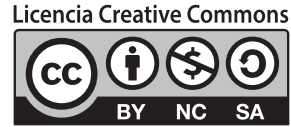




\section{RESUMEN}

En los últimos años, en el marco del derecho internacional de los derechos humanos, se ha avanzado en la protección y reivindicación de los derechos de las personas LGBTI, ${ }^{1}$ tal es el caso de la Opinión Consultiva OC-24/17, la cual representa un antes y un después en el marco del reconocimiento de los derechos de igualdad y no discriminación de la comunidad LGBTI. En esta decisión histórica, la Corte declaró que la Convención Americana de Derechos Humanos protege derechos como el cambio de nombre, la rectificación de los registros públicos y documentos de identidad en el marco de la protección de la identidad de género; también extendió los mecanismos legales existentes al matrimonio de parejas del mismo sexo. Esta resolución ha implicado una serie de enfoques y debates internos en los distintos Estados que son parte de la Convención Americana. El objetivo de este artículo es analizar el contenido de la opinión consultiva en relación con el matrimonio igualitario en el marco de la Constitución de la República del Ecuador, así como de las obligaciones asumidas por el Estado el marco de la comunidad internacional.

Palabras Clave: Corte IDH- Opinión Consultiva OC-24/17- Matrimonio igualitarioDiscriminación-Igualdad y no discriminación-orientación sexual.

\section{ABSTRACT}

In recent years, the framework of International Human Rights Law has advanced in the protection and claim of the rights of the persons LGBTI; This is the case of the Advisory Opinion OC-24/17, it represents a significant step forward in acknowledging of the rights of equality and non-discrimination for the LGBTI community. In a landmark decision, the Court declared that the American Convention on Human Rights protects rights as the change of name and the rectification of public records and identity documents to conform to a person's gender identity. Furthermore, the Inter-American Court of Human Rights extended all existing legal mechanisms, including the marriage to same-sex couples. This resolution has involved a series of approaches both against and in favor of its implementation in the domestic legislation of the States parties, as in the administrative processes of registry change. The objective of this article is to analyze the content of the advisory opinion with regard to equal marriage in the context of the Constitution of Ecuador, as of the obligations assumed by the state in the framework of the international community. KeYwords: Inter-American Court of Human Rights- Opinion OC-24/17- Equal marriage- Discrimination- Equality-Sexual Orientation.

1. Lesbianas, gays, bisexuales, transexuales e intersexuales. 


\section{INTRODUCCIÓN}

T a Opinión Consultiva OC-24/17 (en adelante Opinión Consultiva) implica un Laso trascendental en el reconocimiento de los derechos de la comunidad LGTBI, especialmente en el concepto de familia diversa. Pese a distintos lineamientos, concepciones filosóficas e incluso religiosas y sociales, la Corte Interamericana de Derechos Humanos (en adelante Corte IDH) mediante su función consultiva deja atrás viejos preceptos y va más allá de los interrogantes planteados por el Estado de Costa Rica. En respuesta a la Opinión Consultiva se ha generado el debate sobre el efecto vinculante en los Estados parte de la Convención Americana sobre Derechos Humanos (en adelante Convención Americana). El objeto del presente artículo se centra en el análisis del matrimonio igualitario a la luz de la Convención Americana: Análisis de la Opinión Consultiva OC-24/17 en el contexto jurídico ecuatoriano.

\section{LA FAMILIA DIVERSA EN EL MARCO DE LA JURISPRUDENCIA DE LA CORTE INTERAMERICANA DE DERECHOS HUMANOS}

El concepto de familia ha sido objeto de distintos debates políticos y sociales en las últimas décadas dando como resultado un proceso de transformación social, jurídica, política en distintos países latinoamericanos. Doctrinariamente se ha considerado que los distintos fenómenos sociales han evolucionado el concepto de familia. No obstante, existen quienes estiman que esta evolución responde a un fenómeno de crisis por el cual atraviesa la familia. Para Ortega Ruiz y Mínguez Vallejos, esta concepción responde a un patrón tradicional del concepto de familia, el cual es de vieja data y se ha constituido por el moralismo de antaño que posee una perspectiva homogénea de sociedad e impide la reconstrucción social de la familia. ${ }^{2}$

De acuerdo con Eichler existen distintos sesgos monolíticos, conservadores e incluso heterosexistas, que impiden visibilizar los distintos tipos de familia. ${ }^{3}$ Oliva Gómez y Villa Guardiola consideran que cada familia tiene su propia composición, dinámica y reglas, así como cultura y economía, por tanto, su conceptualización debe

2. Pedro Ortega Ruiz y Ramón Mínguez Vallejo, "Familia y transmisión de valores", Teoría de la Educación, 15 (2004): 33-56, 〈doi.org/10.14201/ted.3022〉.

3. Margrit Eichler, "Cambios familiares: del modelo patriarcal al modelo de responsabilidad individual en la familia”, en El género en el derecho. Ensayos críticos, comp. por Ramiro Ávila, Judith Salgado y Lola Valladares (Quito: Ministerio de Justicia y Derechos Humanos, 2009), 468-71. 
ser flexible. ${ }^{4}$ En este sentido hablar de la existencia de un tipo tradicional nuclear de familia es imposible, así lo especifica la Observación General n. ${ }^{\circ} 19$, al considerar que el concepto de familia puede deferir entre los distintos Estados, por lo tanto, es imposible establecer un concepto de familia uniforme. ${ }^{5}$

Para Juan Marco Vaggione existen dos tendencias claras que deben diferenciarse en el concepto de familia: la primera comprende la familia como una institución única, basada en la heterosexualidad y se constituye por un concepto heteronormativo regulado por la moralidad; y la segunda, el reconocimiento de la familia como una realidad múltiple y diversa mediante un concepto incluyente a las personas LGBTI. ${ }^{6}$

En el desarrollo de la conceptualización de la familia diversa en el ámbito de la Corte Interamericana de Derechos Humanos encontramos distintas sentencias que permiten contextualizar el reconocimiento de la familia diversa a la luz del principio de igualdad y no discriminación: En primer lugar, encontramos la Sentencia de la Corte IDH sobre el caso Atala Riffo vs. Chile (2012). En este caso consideró que no existe un concepto único de familia, ya que no existe un modelo único de convivencia familiar y rechazó las construcciones clásicas de familia normal, familia tradicional, o mejor familia que se usan para limitar el ejercicio de los derechos de las personas LGTBI. ${ }^{7}$ La Corte IDH consideró que, en el marco de la Convención Americana, la discriminación con base en la orientación sexual se encuentra prohibida, ya que un derecho reconocido no puede ser negado o restringido, por lo cual los Estados parte de la Convención Americana, al suscribir una cláusula abierta de no discriminación, no pueden alegar su nivel de desarrollo político social como razonamiento para discriminar. En consecuencia, deben abstenerse de realizar acciones que, directa o indirectamente, puedan crear situaciones de discriminación. ${ }^{8}$

En segundo lugar, el caso Duque vs. Colombia (2016), centra el tema de prestaciones sociales en parejas del mismo sexo. Este es el caso de una persona que no pudo acceder a este beneficio en virtud de su orientación sexual, ya que no cumplía con los estándares establecidos sobre el concepto de familia tradicional, excluyendo así, las

4. Eduardo Oliva Gómez y Vera Judith Villa Guardiola, "Hacia un concepto interdisciplinario de la familia en la globalización”, Justicia Juris, 10, n. ${ }^{\circ} 1$ (2014): 11-20, 〈doi:10.15665/rj. v10i1.295〉.

5. ACNUDH, Observación General, n. ${ }^{\circ}$ 19, 27 de julio de 1990, HRI/GEN/1/Rev.9 (vol. I).

6. Juan Marco Vaggione, "Las familias más allá de la heteronormatividad", en La mirada de los jueces. Sexualidades diversas en la jurisprudencia latinoamericana, ed. por Cristina Motta y Macarena Sáez (Bogotá: Red Alas, 2008), 16.

7. Corte IDH, "Sentencia de 24 de febrero de 2012 (Excepciones Preliminares, Fondo, Reparaciones y Costas)", Caso Atala Riffo y niñas vs. Chile, 24 de febrero de 2012, párrs. 107-110, 〈http://www.corteidh.or.cr/ docs/casos/articulos/seriec_239_esp.pdf).

8. Ibíd., párrs. $72,73,80$ y 93 . 
diversas formas de familia. Con respecto a la discriminación en el marco de las prestaciones sociales, la Corte IDH consideró que la distinción entre las parejas del mismo sexo que son excluidas del derecho a la pensión, y las parejas de hecho compuestas por personas de distintos sexos que sí reciben el beneficio de la pensión, no es razonable, ni objetiva, ni existen factores que justifiquen la existencia de la distinción. ${ }^{9}$

Estas sentencias demuestran, en virtud del principio de igualdad y no discriminación, que no existe un concepto estático de familia.

\section{LA FAMILIA DIVERSA, EL MATRIMONIO CIVIL Y LA GARANTÍA DEL EJERCICIO DE LOS DERECHOS DE LAS PAREJAS DEL MISMO SEXO EN LA OPINIÓN CONSULTIVA OC-24/17}

La Opinión consultiva OC-24/17 ha representado un avance en el marco del reconocimiento de la familia diversa. En este sentido, para la Corte IDH la familia está protegida en el marco de la Convención Americana específicamente en el artículo 17. No obstante, la Corte IDH considera que la Convención, al realizar una definición restrictiva del matrimonio o como debe estar formulada una familia, no implica que esta forma de familia sea la única protegida por la Convención; todo lo contrario, la Corte IDH realiza un análisis sobre los distintos instrumentos internacionales concluyendo que ninguno contiene la definición de la palabra familia, sino que existe una formulación más amplia, como es el caso de la Declaración Americana y el Protocolo de San Salvador que se refieren al derecho de "toda persona" de constituir una familia, de modo que ninguno de esos instrumentos hacen alusión al sexo, género o a la orientación sexual de las personas, como tampoco hace alusión a un modelo de familia en particular. ${ }^{10}$ Por lo tanto, no se protege un determinado modelo de familia. Esto se debe a que la definición de familia no es exclusiva de aquella integrada por parejas heterosexuales, por lo que el vínculo familiar puede derivar de una relación del mismo sexo. ${ }^{11}$

9. Corte IDH, "Sentencia de 21 de noviembre de 2016 (Excepciones Preliminares, Fondo, Reparaciones y Costas)", Caso Duque vs. Colombia, 21 de noviembre de 2016, párr. 106, 〈http://www.corteidh.or.cr/docs/ casos/articulos/seriec_310_esp.pdf).

10. Corte IDH, "Opinión Consultiva OC-24/17 de 24 de noviembre de 2017”, Opinión Consultiva OC-24/17 (Identidad de género, e igualdad y no discriminación a parejas del mismo sexo), 24 de noviembre de 2017, párrs. 181-4, «http://www.corteidh.or.cr/docs/opiniones/seriea_24_esp.pdf〉.

11. Ibíd., párr. 218. 
La interpretación restrictiva del concepto de familia que excluya la protección interamericana sobre el vínculo afectivo entre parejas del mismo sexo frustra el objeto y fin de la Convención. ${ }^{12}$ Esto se debe a que el vínculo afectivo que protege la Convención es imposible de cuantificar, por tanto, el concepto de familia debe ser entendido de una manera flexible amplia, incluso extendiendo esta protección a aquellas familias poligámicas, ya que no existen motivos para desconocer el vínculo familiar de las parejas del mismo sexo e incluso a familias conformadas por personas de diversas identidades de género y orientación sexual. ${ }^{13}$

Con respecto del matrimonio, la Corte IDH considera que el trato diferente que existe entre parejas heterosexuales y aquellas del mismo sexo, en la forma en que puedan fundar una familia, no logra superar el test estricto de igualdad, pues no existe una finalidad que sea convencionalmente aceptable para que esta distinción sea considerada necesaria o proporcional. ${ }^{14} \mathrm{El}$ negar el derecho de acceder a la institución del matrimonio típicamente por no cumplir el fin de la procreación es incompatible con el artículo 17 de la Convención. ${ }^{15}$

La Corte IDH ha observado que la oposición del matrimonio de personas del mismo sexo está basada en convicciones religiosas o filosóficas; sin embargo, estas convicciones no pueden ser utilizadas como parámetro de convencionalidad o condicionar lo que la Convención establece respecto la discriminación basada en la orientación sexual. ${ }^{16}$ Asimismo, la creación de una institución similar a la institución del matrimonio para la unión entre parejas del mismo sexo que produzca los mismos efectos carece de sentido y no es admisible ya que esta distinción es discriminatoria e incompatible con la Convención. De este modo, mediante el estereotipo de heteronormatividad, existiría un matrimonio para quienes son considerados normales y otra institución para quienes han sido considerados anormales, lo que para la Corte IDH no es admisible la existencia de dos clases de uniones solemnes para consolidar jurídicamente la comunidad de convivencia heterosexual y homosexual, ya que este acto es discriminatorio. ${ }^{17}$ Por lo tanto, mientras exista la voluntad de conformar una familia, existe un vínculo que merece igualdad de derechos y protección sin importar la orientación sexual de sus contrayentes. Esto no significa que se reste valor a la institución del matrimonio, sino, por el contrario, es necesario para reconocerle igual

\footnotetext{
12. Ibíd., párr. 189.

13. Ibíd., párrs. 179, 190 y 191.

14. Ibíd., párr. 220.

15. Ibíd., párr. 221.

16. Ibíd., párr. 223.

17. Ibíd., párrs. 218 y 224.
} 
dignidad a personas que pertenecen a un grupo humano históricamente oprimido y discriminado. ${ }^{18}$

La Corte IDH considera que los Estados deben garantizar el acceso a todas las figuras ya existentes en los ordenamientos jurídicos internos, para asegurar la protección de todos los derechos de las familias conformadas por parejas del mismo sexo, sin discriminación con respecto a las que están constituidas por parejas heterosexuales. ${ }^{19}$

\section{RECONOCIMIENTO CONSTITUCIONAL \\ DE LOS "DIVERSOS TIPOS DE FAMILIA" A LA LUZ DEL PRINCIPIO DE IGUALDAD Y NO DISCRIMINACIÓN -UNIÓN DE HECHO Y MATRIMONIO- EN EL CONTEXTO ECUATORIANO}

Para hablar de reconocimiento constitucional es imprescindible hablar de la forma de Estado y, específicamente del Estado ecuatoriano, un Estado constitucional de derechos ${ }^{20}$ y justicia, social, democrático, soberano, independiente, unitario, intercultural, plurinacional y laico. ${ }^{21}$ La Constitución liberal de 1906 marcó la separación absoluta entre Estado e Iglesia, eliminando toda mención que se hacía en otras constituciones sobre Dios y la religión; a partir de 1906 los asuntos religiosos dejan de tener un interés político para el Estado. ${ }^{22}$

Lo laico cobra importancia en la progresión de los derechos de familias diversas, en tanto la Iglesia se ha caracterizado por mantener una postura radical y contraria respecto a la posibilidad de establecimiento de familias que no sean conformadas mediante matrimonio y en la relación binaria de hombre-mujer.

De esta manera, el reconocimiento de los derechos en una carta constitucional es importante, ya que representa una forma de interacción entre el Estado y la sociedad. Además, la esencia de la Constitución como cuerpo legal implica que se pueda mate-

18. Ibíd., párrs. 33 y 224 .

19. Ibíd., párrs. 218 y 228.

20. La Constitución determina el contenido de la ley, el acceso y el ejercicio de la autoridad y la estructura de poder. La Constitución es material, orgánica y procedimental. Ramiro Ávila, La Constitución del 2008 en el contexto andino (Quito: Ministerio de Justicia y Derechos Humanos, 2010).

21. Defender sistemas de exclusión de derechos no contribuye a la construcción de democracias robustas ni de un Estado constitucional de Derechos y Justicia. Voto concurrente: juez Ramiro Ávila Santamaría. Ecuador Corte Constitucional, "Sentencia (matrimonio igualitario)", en Juicio n. ${ }^{\circ} 111-18-C N / 19$ junio-CC, 12 de junio de 2019, 2.

22. Enrique Ayala Mora, ed., Historia constitucional. Estudios comparativos (Quito: Universidad Andina Simón Bolívar, Sede Ecuador / Corporación Editora Nacional, 2014). 
rializar, con ello, que los derechos sean reales en su aplicación y no solamente postulados plasmados en el papel sin ningún efecto práctico para la sociedad.

Se cambia la concepción de la ley como fuente de prescripción de los lineamientos estatales y en consecuencia el ejercicio y la aplicación de los derechos. Respecto de la función unificadora de la Constitución, y la importancia de las constituciones contemporáneas como remedio a un orden jurídico que no ha tomado en cuenta a derechos más altos, que incluso obligan al legislador. ${ }^{23}$

En el contexto de los derechos que se consideran transversales en la Constitución ecuatoriana se encuentran el derecho a la igualdad y no discriminación, contenido en la Convención Americana, relevante por la interdependencia que tiene con otros derechos.

Robert Alexy formula una teoría basada en todos los escenarios posibles en los cuales se desarrolla la igualdad, así como su aplicación. Esta teoría aplicada en relación directa entre el principio/derecho a la igualdad y las familias diversas podría interpretar "La Igualdad en la Aplicación y en la Formulación del Derecho", distinguiendo entre un derecho general de igualdad y derechos especiales de igualdad.

Es de esta manera, cuando un ordenamiento jurídico considera a todas las personas como iguales ante la ley, que se interpreta como un mandato de igualdad en la aplicación del derecho. El mandato de igualdad exige en principio que todos sean tratados igual por el legislador. Lo anterior no quiere decir que el legislador tiene que colocar a todos en las mismas posiciones jurídicas, propiedades naturales o situaciones fácticas, ya que esto conduciría a normas no funcionales, disparatadas e injustas.

Respecto del principio general de igualdad dirigido específicamente al legislador, no se puede exigir que todos sean tratados de la misma manera y que todos deban ser iguales en todos los aspectos, y es bajo esta conclusión que Alexy formula la conocida expresión "tratar igual a lo igual y desigual a lo desigual", pero hay que buscar las razones suficientes para explicar un tratamiento desigual. Es decir, "Si no hay ninguna razón suficiente para la permisión de un tratamiento desigual, entonces está ordenado un tratamiento igual". ${ }^{24}$

La CRE da un tratamiento a la igualdad bajo dos enfoques: como principio ${ }^{25} \mathrm{y}$ como derecho. ${ }^{26}$ La premisa de igualdad general de Alexy se ve manifestada en el art.

23. Gustavo Zagrebelsky, El derecho dúctil. Ley, derechos, justicia (Madrid: Trotta, 1997).

24. Robert Alexy, Teoría de los derechos fundamentales (Madrid: Centro de Estudios Políticos y Constitucionales, 2001), 383.

25. Ecuador, Constitución de la República del Ecuador, Registro Oficial 449, 20 de octubre de 2008, art. 11.2.

26. Ibíd., art. 66.4, "El Estado reconoce y garantiza a las personas el "derecho a la igualdad formal, igualdad material y no discriminación". 
11 de la CRE. La institución de la familia diversa estaría bajo el supuesto de igualdad general. La CRE establece que los ciudadanos no pueden ser discriminados por su identidad de género, ni por su orientación sexual.

Se podría expresar que las familias diversas constitucionalmente gozan de un reconocimiento igualitario, ${ }^{27}$ porque así el Estado lo reconoce; es entonces que el análisis debe profundizarse para poder conocer si los vínculos jurídicos y/o de hecho son iguales para todas y todos los ciudadanos. ${ }^{28}$

Uno de los vínculos por el cual se puede formar una familia son las uniones de hecho, que se encuentran en el art. 68 de la CRE: "La unión estable y monogámica entre dos personas libres de vínculo matrimonial que formen un hogar de hecho, por el lapso y bajo las condiciones que señale la ley, generará los mismos derechos y obligaciones que tienen las familias constituidas mediante matrimonio". En este punto cabe analizar la titularidad del derecho para establecer la unión de hecho como manera de conformación de la familia. El artículo citado habla de "personas"; de acuerdo con lo mencionado, "personas" no diferencia ningún tipo de índole étnico, social o de género, con lo que se concluye que todos los ciudadanos pueden acceder a la unión de hecho sin ningún tipo de discriminación.

Las condiciones que señala la ley exigen que debe existir normativa secundaria que regule las formalidades por la cuales las personas podrán ejercer su derecho a formar una familia. Es necesario recordar que la CRE contiene el principio consagrado en el art. 11.4, que ninguna norma jurídica podrá restringir el contenido de los derechos; entonces, cuando una norma jurídica desarrolle las condiciones y/o requisitos, estas no podrían atentar al espíritu constitucional. En la Constituyente de 2008 se incluyó el vínculo de la unión de hecho a las parejas del mismo sexo: un avance significativo en el reconocimiento de los derechos de personas LGBTI, y una manera viable de formar un vínculo jurídico familiar, sin ser el único. ${ }^{29}$

27. Art. 67.- Se reconoce la familia en sus diversos tipos. El Estado la protegerá como núcleo fundamental de la sociedad y garantizará condiciones que favorezcan integralmente la consecución de sus fines.

28. Sentencia n. ${ }^{\circ}$ 11-18-CN/19 (matrimonio igualitario), juez ponente: Ramiro Ávila Santamaría, 14, párrafos 51,76 .

Al respecto, la Corte Constitucional del Ecuador en la "Sentencia 'Caso Satya'", en Juicio n. ${ }^{\circ}$ 184-18 Sep.-CC, 29 de mayo de 2018, expresó: "Un aspecto fundamental que debe ser leído en los términos establecidos, es el vínculo filial que se forma entre los padres y madres para con sus hijos, aspecto que ha de ser garantizado desde la diversidad de núcleos familiares existentes, en consideración al goce en condiciones de igualdad que poseen las uniones de hecho y el especial reconocimiento que la Constitución consagra hacia las familias en sus diversos tipos", 72 .

29. Sentencia n. ${ }^{\circ} 11-18-\mathrm{CN} / 19$ (matrimonio igualitario), juez ponente: Ramiro Ávila Santamaría, 18, párrafo 200. La unión de hecho y el matrimonio, a pesar de la declaración constitucional de que genera los mismos 
Se debe analizar si esta genera los mismos derechos y obligaciones que las familias constituidas mediante matrimonio. Alexy argumenta que la "razón suficiente" consiste en una carga de argumentación, tanto para los tratamientos iguales como para los desiguales, es decir, la máxima de igualdad se convierte en una exigencia de fundamentación. ${ }^{30}$

En el tema de las familias diversas prima facie no se detecta ningún tratamiento desigual constitucionalmente establecido, sino, por el contrario, se establece igualdad total de sus derechos. Una sociedad sin discriminación ni violencia tiene que ser pluralista por definición, aceptar la diversidad humana sin que se implante un solo modelo sobre otro.

En ese sentido, no se podría hablar de "la familia", pues lo que cabe es una diversidad de "familias", en lo que las defina sea el mutuo consentimiento de querer compartir un vínculo y permanecer en él, y no elementos extraños, como la imposición de una ley, o por parentescos sanguíneos. ${ }^{31}$ Este tipo familiar, tan común en Latinoamérica, nos permite encontrar familias no comprendidas como la definición legal lo presupone; $\mathrm{y}$, por ende, estas deben merecer igual protección y atención en el desarrollo de la sociedad que las derivadas de un acto fundacional volitivo, como lo es el matrimonio. ${ }^{32}$ Así lo determinó la Corte Constitucional del Ecuador:

Esta concepción implica una nueva determinación de la familia, pues la concepción y protección de una sola forma familiar aislada de las realidades plurales, prima facie, implica una desprotección de los núcleos reconocidos por la norma constitucional; consecuentemente, el no reconocimiento y garantía de los diversos tipos de familia involucra una actuación u omisión contraria a la Constitución, que a su vez demanda una intervención de la justicia constitucional. Dicho lo cual, la familia adquiere una diversidad de formas de constitución. ${ }^{33}$

El matrimonio se establece como "unión entre hombre y mujer"; acorde con el hilo teórico, existe una desigualdad de tratamiento de quienes pueden acceder al matrimonio

derechos y obligaciones, tienen regulaciones diferentes legalmente y también apreciaciones culturales diversas.

30. Robert Alexy, Teoría de los Derechos fundamentales, 383.

31. Al respecto, la Corte Constitucional del Ecuador en la "Sentencia 'Caso Satya'", en Juicio n. ${ }^{\circ} 184-18$ Sep.-CC, 29 de mayo de 2018, expresó: "La familia conformada por las señoras Nicola Rothon, Helen Bricknell y la niña Satya Amani goza de protección constitucional, por lo que su vínculo filial debe ser garantizado en forma igualitaria a la protección que se otorga a las familias por vínculo matrimonial", 72.

32. Marcela Huaita Alegre, Declaración Universal de Derechos Humanos: Texto y comentarios inusuales (San José: ILANUD, 2001), 257-62.

33. Ecuador Corte Constitucional, "Sentencia 'Caso Satya'", en Juicio n. ${ }^{\circ}$ 184-18 Sep.-CC, 29 de mayo de 2018, 83 . 
como una de las maneras para formar una familia. ${ }^{34}$ Cabe preguntarse, entonces, si existió una "razón suficiente" para realizar la distinción, o si la fundamentación constituyente fue lo suficientemente sustentada para permitir que se genere este tipo de distinción.

El Consejo de Estado de Colombia determinó que la figura de familia va más allá del matrimonio. La disposición de conformar una familia nace de la decisión libre de dos personas que asumen lazos de solidaridad, apoyo, cariño, amor y convivencia. En el fallo se hizo un análisis de la evolución de la figura de familia como institución sin importar raza, estatus u orientación sexual, para conformar de manera libre y autónoma una familia.

El art. 66.9 de la CRE reconoce: "El derecho a tomar decisiones libres, informadas, voluntarias y responsables sobre su sexualidad, y su vida y orientación sexual. El Estado promoverá el acceso a los medios necesarios para que estas decisiones se den en condiciones seguras". Este derecho debe ser respetado por el Estado, al concluir que como principio democrático no se puede avalar "un consenso mayoritario que relegue a los homosexuales al nivel de ciudadanos de segunda categoría", irrespetando el derecho expreso a la sexualidad y su orientación sexual. El principio de igualdad se opone, de manera radical, a que a través de la ley por razones de orden sexual se somete a una minoría que no comparta los gustos, hábitos y prácticas sexuales de la mayoría a un trato diferente. ${ }^{35}$

Por último, dentro de los derechos de libertad en el art. 66.20 se garantiza "el derecho a la intimidad personal y familiar". Cuando las personas expresan la voluntad de formar una familia, no se debería distinguir la orientación sexual de las personas que deseen conformarla. ${ }^{36}$ Para ello, la familia homosexual surge de la "voluntad responsable" de conformarla; que surge de las exigencias de los derechos al libre desarrollo de la personalidad, a la autonomía, la autodeterminación y a la igualdad. Así también, es improcedente "efectuar un pronunciamiento de carácter general conforme al cual

34. Sentencia n. ${ }^{\circ}$ 11-18-CN/19 (matrimonio igualitario), juez ponente: Ramiro Ávila Santamaría, 43, párrafo 210, expresa: "Efectivamente, cualquier persona en el Ecuador puede escoger, para formar una familia, la unión de hecho. De esta norma, sin embargo, no se deriva una obligación para las parejas del mismo sexo de utilizar esta figura legal para acceder al derecho de la familia ni tampoco podría ser considerada como la única opción".

35. Ibíd.

36. Al respecto, la Corte Constitucional del Ecuador en la "Sentencia 'Caso Satya", en Juicio n. ${ }^{\circ} 184-18$ Sep.-CC, 29 de mayo de 2018, expresó: Sobre la base de la igualdad formal de derechos y obligaciones, la unión de hecho de la señora Nicola y Helen, posee el mismo derecho a registrar la filiación respecto a la doble maternidad de su núcleo hacia su hija, así como la tienen los núcleos heterosexuales respecto de sus hijos. En este sentido, la igualdad en cuanto a norma imperativa del derecho, obliga una aplicación normativa en la que cada familia sea considerada como igual en las diversas y especiales condiciones de su constitución. 
toda diferencia de trato entre ambos tipos de pareja (homosexuales y heterosexuales) resulta contraria a la Constitución". ${ }^{37}$ En los casos de familia se podría producir lo que los magistrados expresan como "déficit de protección". ${ }^{38}$

Con respecto de los derechos de libertad y su aplicación en el tratamiento de la igualdad, se han tomado la jurisprudencia de la Corte colombiana y la reciente Sentencia de la Corte Constitucional del Ecuador. Es posible mencionar que nuestra Constitución, al solo proteger aparentemente a los matrimonios heterosexuales, violaría la dignidad humana de los homosexuales, reduciéndoles la posibilidad de vivir planamente dentro de su plan de vida.

La Constitución con base en el principio de igualdad y no discriminación es compatible con el desarrollo jurisprudencial de la Corte IDH y de la Opinión Consultiva; y tanto la unión de hecho como el matrimonio son maneras de conformación formal de la familia. El principio de igualdad finalmente está accesible a todos los ciudadanos sin dependencia de su orientación sexual como manera de constitución de familias más diversas. ${ }^{39}$

\section{COMPATIBILIDAD DE LA OPINIÓN CONSULTIVA OC/24-17 EN RELACIÓN CON LOS DISTINTOS TIPOS DE FAMILIA Y EL ORDENAMIENTO JURÍDICO INTERNO, EN EL CONTEXTO DE LA CONSTITUCIÓN DE 2008}

Como se viene analizando, en la CRE en el art. 11 se enuncian los principios de aplicación de los derechos que constituyen el pilar fundamental para el desarrollo efectivo y eficaz de los mismos en un Estado. Bajo estas consideraciones, los siguientes principios tienen directa relación con los derechos a una familia diversa, reconocidos constitucionalmente:

- El principio de igualdad y no discriminación: las familias tienen que ser tratadas de forma igual y sin ningún tipo de discriminación; si no existe una razón suficiente para un trato diferenciado, se considera un trato discriminatorio.

- Aplicación y justiciabilidad directa de derechos: ${ }^{40}$ no se puede alegar falta de normativa inferior para el desarrollo de los derechos en cuanto al reconoci-

37. Ibíd.

38. Ibíd.

39. Sentencia n. ${ }^{\circ} 11-18-\mathrm{CN} / 19$ (matrimonio igualitario), juez ponente: Ramiro Ávila Santamaría, 12.

40. Voto concurrente Caso 10-18-CN (matrimonio entre personas del mismo sexo), juez Ramiro Ávila Santamaría, párrafos, 10, 11, 12 . 
miento de la familia diversa. El derecho reconocido respecto de la unión de hecho que faculta a personas homosexuales formar una familia a través de esta institución no requiere la existencia de algún tipo de normativa diferenciada. A pesar de que este derecho fue reconocido en la constituyente de 2008, es recién a partir del 15 de septiembre de 2014 que entró en vigor la resolución que permite formalizar la unión de hecho mediante la inscripción en el Registro Civil; para ello se debió esperar seis años una resolución del Registro Civil para otorgarles plenos derechos.

- Prohibición de restricción normativa: no permite que una ley inferior a la Constitución restrinja el contenido esencial de los derechos. Para el caso de familias diversas cualquier norma que pudiese crearse para el efecto se deberá acoger al deber de protección y garantía que le ofrece la Constitución.

- Progresividad y no regresividad de los derechos: derechos nunca antes reconocidos han marcado hitos en la sociedad ecuatoriana: derechos de la naturaleza, el derecho a la resistencia y derechos de familias diversas. Más allá de un mero reconocimiento constitucional, la progresividad debe verse reflejada en políticas y normas que emanen del poder, que permitan que el derecho sea tangible.

El Código Civil ecuatoriano en el art. 81 prescribe que el "Matrimonio es un contrato solemne por el cual un hombre y una mujer se unen con el fin de vivir juntos, procrear y auxiliarse mutuamente". La CRE manifiesta en el art. 67 que "El matrimonio es la unión entre hombre y mujer, se fundará en el libre consentimiento de las personas contrayentes y en la igualdad de sus derechos, obligaciones y capacidad legal". La convivencia y el auxilio mutuo no necesariamente se dan entre hombre y mujer, por lo que sería discriminatorio pensar que estas cualidades devienen intrínsecamente de la condición biológica del ser humano, al comprenderlo que se expresan en el antagonismo entre hombre y mujer.

Otro elemento constitutivo en el matrimonio es la procreación. ${ }^{41}$ Frente a esta característica se ha considerado que:

La procreación no es una obligación, sino una posibilidad que se les ofrece a los casados y que el legislador, atendiendo a lo que suele ser normal en la realidad, reconoció, otorgándole el carácter de finalidad del matrimonio, lo que no implica la imposición de una obligación inexcusable de tener hijos, ni un desconocimiento de los derechos a la autodeterminación reproductiva, a la autonomía individual y al derecho al libre desarrollo de la

41. Sentencia n. ${ }^{o}$ 10-18-CN/19, jueza ponente: Ali Lozada Prado, 10. 
personalidad. [...] la capacidad de engendrar no es un requisito que deba ser satisfecho para poder celebrar este contrato. ${ }^{42}$

Por ello, es necesario precisar que "El matrimonio y la familia son previos a la Constitución, y es precisamente el modelo que la Constitución acoge el que delimita la capacidad de regulación que tienen los poderes públicos". ${ }^{43}$ Por ende, el matrimonio y la familia deben reflejar una realidad social, acorde a la evolución del derecho. Pese a lo anterior, en la doctrina se han diferenciado las uniones cuyos miembros no pueden casarse: aquellos que no pueden casarse por tener constitucionalmente vedado el acceso al matrimonio. ${ }^{44}$ Hasta hoy, el contrato de matrimonio ha proporcionado una protección mayor que cualquier otra figura jurídica, por lo que al prohibir explícitamente el matrimonio a cierto tipo de personas genera un nivel de protección menor a las personas que no pueden acceder a él.

Negar el matrimonio a las personas no heterosexuales "perpetúa un conjunto de prejuicios atávicos de origen fundamentalmente religioso que niegan el derecho a la igualdad efectiva y la protección contra la discriminación de las personas pertenecientes a las minorías sexuales". ${ }^{45}$ Es necesario, por lo tanto, que "el derecho al reconocimiento de las uniones legales de personas del mismo sexo constituye una constante de los derechos modernos y un deber de los poderes públicos, pues la falta de tal reconocimiento representa, una discriminación indebida y una violación de los derechos constitucionales a la igualdad y a la no- discriminación". ${ }^{4}$

En consecuencia, es posible concluir que existen principios en la Constitución como los de igualdad y no discriminación, así como la prohibición de restricción normativa, que podrían estar en contradicción con los artículos constitucionales referentes a los derechos de la familia y en específico al reconocimiento de la familia diversa.

Lo anterior se sitúa en la doctrina que Bachof denominó como "Normas constitucionales inconstitucionales", en cuanto a "Las distintas posibilidades de normas constitucionales inconstitucionales (inválidas)". Explica que, "aunque en el seno de una Constitución generalmente eficaz, una de las normas no satisfaga las condiciones dispuestas en ella para que pueda ser eficaz, cabe hablar de una norma constitucional

42. Corte Constitucional de Colombia, sentencia C-577/11.

43. Pablo Nuevo, Reflexiones Constitucionales a propósito del llamado "Matrimonio Homosexual" (Barcelona: Universidad Abat Oliva, 2006), 36.

44. Corte Constitucional de Colombia, sentencia C-577/11.

45. Beatriz Espinoza, ed., Cuerpos y diversidad sexual: aportes para la igualdad y el reconocimiento (Bogotá: Pontificia Universidad Javeriana, 2008), 22.

46. Ibíd., 25. 
"inconstitucional" siendo, por lo tanto, inválida". ${ }^{47}$ Así en el caso de la unión de hecho que se respetan los principios de igualdad y no discriminación, no obstante, en el caso del matrimonio, la norma no satisfacía los principios constitucionales, debido a la limitación el acceso y ejercicio de este derecho a personas que tienen una orientación sexual diferente. Esta norma no "cumpliría las condiciones dispuestas para ser eficaz"; de esta manera se podría declarar la invalidez de la misma.

Entendiendo que el carácter material de la CRE contiene los principios y derechos constitucionales, que son jerárquicamente superiores a cualquier otra norma, es posible indicar que la restricción tanto del matrimonio como de la adopción a parejas del mismo sexo contraviene la Constitución material que enuncia a la igualdad como principio para el ejercicio de los derechos. La contradicción podría declarar la inconstitucionalidad de la norma.

\section{DEBATE SOBRE LOS PRINCIPALES PROBLEMAS QUE ENFRENTA LA OPINIÓN CONSULTIVA EN EL RECONOCIMIENTO DE LOS DERECHOS DE LA COMUNIDAD LGBTI}

El carácter vinculante que posee una opinión consultiva con respecto a los Estados Parte de la Convención Americana ha sido el principal debate en la comunidad latinoamericana, ya que no se trata de una sentencia resuelta por la Corte IDH, por tanto, no está sujeta a las potestades de ejecución. Además, no existe un desarrollo jurisprudencial que indique que las opiniones consultivas tengan un efecto vinculante, como tampoco se encuentra expresamente establecido en la Convención Americana, constituyendo el principal obstáculo que enfrenta la comunidad LGBTI para solicitar el cumplimiento de la Opinión Consultiva. ${ }^{48}$

Si bien la Corte IDH ha manifestado que las opiniones consultivas no poseen efecto vinculante ${ }^{49}$ en el desarrollo de las distintas opiniones consultivas desde la OC16/99 se le han atribuido otras funciones como: la función interpretativa, la función

47. Otto Bachof, Normas constitucionales inconstitucionales? (Lima: Palestra, 2010), 72.

48. Ecuador Corte Constitucional, "Sentencia (matrimonio igualitario)", en Juicio n. ${ }^{\circ}$ 111-18-CN/19 junio$C C, 12$ de junio de 2019, 9.

49. Corte IDH, "Opinión Consultiva, OC-1/82, del 24 de septiembre de 1982", Opinión Consultiva OC- 1/82 (Otros Tratados. Objeto de la Función Consultiva de la Corte (art. 64 Convención Americana sobre Derechos Humanos)), 24 de septiembre de 1982, párr. 51, 〈https://www.catalogoderechoshumanos.com/ opinion-consultiva-1-cidh/>. 
preventiva y la función de guía de actuación de los Estados en la protección de Derechos Humanos; ${ }^{50}$ por tanto, posee efectos jurídicos innegables. ${ }^{51}$

Para Jorge Roa, el hecho de que existan al menos veinte sentencias contenciosas de la Corte IDH, en las que se aplican estrictamente criterios formulados en las opiniones consultivas, prueba que la Corte entiende que la fuerza horizontal de sus opiniones consultivas es absoluta. ${ }^{52}$ Ángeles Cruz Rosel y Carlos Escoffipe Duarte destacan que, en el ejercicio de la función consultiva de la Corte IDH, si bien no existen partes involucradas y no existe un litigio para resolver, cumplen la función propia de un control de convencionalidad preventivo. ${ }^{53}$

Es importante destacar la interrelación que sostiene el Derecho Constitucional, con el Derecho Internacional de los Derechos Humanos y en virtud del principio pro homine como principio rector en la relación entre el derecho interno y el derecho internacional y como principio de aplicación de los derechos humanos. En virtud de la Convención Americana, el principio pro homine sirve como herramienta para vincular a los dos sistemas normativos hacia una mejor defensa de los derechos de las personas independientemente de que norma sea considerada como superior. ${ }^{54}$

En este contexto el primer elemento que ha defendido el efecto vinculante de la Opinión Consultiva deviene de la jerarquía normativa existente en los distintos Estados de la región. En el caso ecuatoriano esta jerarquía se encuentra contenida en el artículo 425 de la Constitución, situando a la Constitución como pilar fundamental del ordenamiento jurídico. Paralelamente, el artículo 424 de la Constitución explica que las normas de derechos humanos prevalecen sobre cualquier otra de derecho interno. La Constitución ecuatoriana considera que los instrumentos ratificados por el Estado que reconozcan derechos más favorables que los contenidos en la Constitución prevalecerán sobre cualquier otra norma jurídica o acto del poder público. En este aspecto

50. Ecuador Corte Constitucional, "Sentencia (matrimonio igualitario)", en Juicio n. ${ }^{\circ} 111-18-C N / 19$ junio$C C, 12$ de junio de 2019, 16.

51. Corte IDH, “Opinión Consultiva, OC-16/99, de 1 de octubre de 1999”, Opinión Consultiva OC-16/99 (El Derecho a la Información sobre la asistencia consular en el marco de las garantías del Debido proceso Legal), de 1 de octubre de 1999, párr. 48, 〈http://www.corteidh.or.cr/docs/opiniones/seriea_16_esp.pdf〉.

52. Jorge Ernesto Roa, La función consultiva de la Corte Interamericana (Bogotá: Universidad Externado de Colombia, 2015).

53. Rafael Rodríguez, "La protección del derecho a la identidad de género de las personas trans en el ordenamiento jurídico peruano desde una mirada dialógica entre el Derecho Constitucional y el Derecho Internacional de los Derechos Humanos: Avances, Retrocesos y desafíos (2014-2018)", Revista del Instituto de la familia, n. 07 (2018): 165-87; Corte IDH, "Sentencia de 20 de marzo de 2013 (Excepciones Preliminares, Fondo, Reparaciones y Costas)", Caso Gelman vs. Uruguay, Sentencia de 20 de marzo de 2013, párr. 69, 〈http://www.corteidh.or.cr/docs/casos/articulos/seriec_221_esp1.pdf〉.

54. Luis Eduardo Vieco, "La Universalización de los Dērechō Humanos", Analecta Política, n. 3 (2012): 165-79. 
la Opinión Consultiva al contener la interpretación de un instrumento de derechos humanos, que contiene la interpretación de derechos "más favorables", prevalece sobre las normas jurídicas internas del país y, como se ha analizado previamente, en virtud del principio de igualdad y no discriminación son compatibles con la Constitución de 2008. El artículo 11.3 de la Constitución ecuatoriana reconoce la aplicabilidad directa de los derechos humanos consagrados en diversos instrumentos internacionales en la materia. En el número 8 de este artículo se reconoce el carácter progresivo de estos derechos, como el deber estatal de interpretarlos a la luz de la jurisprudencia. Las obligaciones asumidas por el Estado Ecuatoriano como Estado parten de un instrumento internacional. La Convención de Viena sobre el Derecho de los Tratados en el artículo 27 y la Convención Americana en el artículo 2 establecen el deber de los Estados de cumplir con lo pactado en tratados internacionales, aun cuando estas disposiciones sean contrarias al ordenamiento jurídico interno. ${ }^{55}$ De acuerdo con el Frente por los Derechos Igualitarios no es necesaria una ley para acatar la opinión consultiva, ya que, en materia de Derechos Humanos, la reserva de ley se aplica cuando se busca establecer un límite o restricción a estos, no cuando se pretende extender o garantizar un derecho determinado; por ende, el disfrute y ejercicio de los derechos humanos no requiere de una ley en sentido estricto. ${ }^{56}$

En el caso de la Corte Constitucional ecuatoriana ha sido considerado en varias sentencias las normas y principios interpretados por la Corte IDH, mediante opiniones consultivas, de tal modo de constituir un instrumento de interpretación sobre un tratado internacional del cual el Ecuador es parte. En la Sentencia n. $.^{\circ} 11-18-\mathrm{CN} / 19$, se considera que el Ecuador tiene la obligación de cumplir de buena fe, sin que se pueda invocar las disposiciones de su derecho interno como justificación del incumplimiento de un tratado. Por tanto, estas son parte del ordenamiento jurídico ecuatoriano y tienen que ser observadas en Ecuador por toda autoridad pública en el ámbito de su competencia. En consecuencia, los derechos y garantías reconocidas en la Opinión Consultiva OC-24/17, que interpreta con autoridad la Convención American, forman parte de lo que se ha conocido como bloque de constitucionalidad, como lo denomina la Corte IDH, y son parte del corpus iuris; esto quiere decir que tienen la misma jerarquía normativa constitucional y son directa e inmediatamente aplicables en el sistema jurídico.

55. Es importante destacar que el Ecuador es Estado Parte de estos dos instrumentos internacionales. Ecuador Corte Constitucional, "Sentencia (matrimonio igualitario)", en Juicio n. ${ }^{\circ} 111-18-C N / 19$ junio-CC, 12 de junio de 2019.

56. FDI, Guía sobre la Opinión Consultiva OC-24/2017 de la Corte IDH: sobre identidad de género, igualdad y no discriminación a parejas del mismo sexo y sus implicaciones jurídicas (San José: FDI, 2018). 


\section{CONCLUSIONES}

La Opinión Consultiva OC-24/17 ha despertado críticas y se considera que la Corte IDH incurrió en el vicio de extra petita, ya que la consulta del Estado costarricense se centraba principalmente en la interpretación de la protección contenida en la Convención Americana sobre el reconocimiento del cambio de nombre de las personas, de acuerdo con la identidad de género; como también solicitó la interpretación con respecto al reconocimiento de los derechos patrimoniales derivados de un vínculo entre personas del mismo sexo. Al respecto, la Corte IDH estimó que la protección de estos derechos trasciende las barreras patrimoniales, proyectándose así, a todos los derechos humanos reconocidos a las parejas heterosexuales. Por tanto, en el marco de garantizar los derechos de las parejas del mismo sexo no es necesaria la creación de nuevas figuras jurídicas, sino que las normas existentes se hacen extensibles a las parejas compuestas por personas del mismo sexo, en virtud del principio pro-persona. Además, este constituye el medio más sencillo y eficaz para asegurar los derechos derivados del vínculo entre parejas del mismo sexo, considerando que los argumentos relacionados con la religión o las concepciones filosóficas que se opongan al reconocimiento de estos derechos no son un argumento válido para negar o restringir derechos. La CRE es la norma suprema para el reconocimiento de deberes y derechos de los ciudadanos y ciudadanas. Ecuador, al ser un Estado constitucional de derechos, reconoce a los mismos como el eje primordial; los cuales deben atravesar todo acto que emane del poder público y privado, con la existencia de las debidas garantías de protección. Entre los derechos reconocidos en la Constitución en el año 2008, se encontraba el reconocimiento de las familias diversas (art. 67). Para las parejas con diferente orientación sexual a la heterosexual, la única manera de conformación de una familia era por medio de la unión de hecho, derecho otorgado con titularidad a todos los ciudadanos, sin importar su orientación sexual, sin embargo, al detectarse una violación al principio/ derecho a la igualdad y no discriminación, y al no existir una razón suficiente para un tratamiento desigual; en junio de año 2019, la Corte Constitucional del Ecuador emitió una sentencia que permite el matrimonio civil a las parejas conformadas por personas homosexuales, como otra manera de conformación de una familia. Es decir, en la actualidad, la conformación de las familias, sea esta diversa o no, en ejercicio y titularidad de sus derechos, es accesible a todos los ciudadanas, pudiendo escoger entre las figuras de la unión de hecho y el matrimonio, sin ninguna razón de restricción normativa o constitucional que vulnere los derechos de las personas con orientaciones sexuales diferentes. 
FORO 32, julio-diciembre 2019

\section{BIBLIOGRAFÍA}

ACNUDH. Observación General, n. ${ }^{\circ}$ 19. 27 de julio de 1990. HRI/GEN/1/Rev.9 (Vol. I).

Alexy, Robert. Teoría de los Derechos fundamentales. Madrid: Centro de Estudios Políticos y Constitucionales, 2001.

Ávila, Ramiro. La Constitución del 2008 en el contexto andino. Quito: Ministerio de Justicia y Derechos Humanos, 2010.

Ayala Mora, Enrique, ed. Historia Constitucional. Estudios Comparativos. Quito: Universidad Andina Simón Bolívar, Sede Ecuador / Corporación Editora Nacional, 2014.

Bachof, Otto. ¿Normas constitucionales inconstitucionales? Lima: Palestra Editores, 2010.

Carbonel, Miguel, ed. Teoría del neoconstitucionalismo. Madrid: Trotta, 2007.

Colombia Corte Constitucional de Colombia. "Sentencia". Juicio n. ${ }^{\circ}$ C-577/11. 26 de julio de 2011.

Corte IDH. "Opinión Consultiva, OC-16/99, de 1 de octubre de 1999”. Opinión Consultiva OC-16/99 (El Derecho a la Información sobre la asistencia consular en el marco de las garantías del Debido proceso Legal). 1 de octubre de 1999, párr. 48. 〈http://www.corteidh. or.cr/docs/opiniones/seriea_16_esp.pdf).

—. "Opinión Consultiva, OC-1/82, del 24 de septiembre de 1982”. Opinión Consultiva OC1/82 (Otros Tratados. Objeto de la Función Consultiva de la Corte (art. 64 Convención Americana sobre Derechos Humanos)). 24 de septiembre de 1982, párr. 51. 〈https://www. catalogoderechoshumanos.com/opinion-consultiva-1-cidh/s.

—. "Opinión Consultiva OC-24/17 de 24 de noviembre de 2017”. Opinión Consultiva OC24/17 (Identidad de género, e igualdad y no discriminación a parejas del mismo sexo). 24 de noviembre de 2017, párrs. 181-4. 〈http://www.corteidh.or.cr/docs/opiniones/seriea_24_ esp.pdf〉.

—. "Sentencia 28 de noviembre de 2012 (Excepciones Preliminares, Fondo, Reparaciones y Costas)". Caso Artavia Murillo y otros ("Fecundación in vitro") vs. Costa Rica. 28 de noviembre de 2012, párr. 145. 〈http://www.corteidh.or.cr/docs/casos/articulos/seriec_257_ esp.pdf〉.

—. "Sentencia de 20 de marzo de 2013 (Excepciones Preliminares, Fondo, Reparaciones y Costas)". Caso Gelman vs. Uruguay. Sentencia de 20 de marzo de 2013, párr. 69. «http:// www.corteidh.or.cr/docs/casos/articulos/seriec_221_esp1.pdf〉.

—. "Sentencia de 21 de noviembre de 2016 (Excepciones Preliminares, Fondo, Reparaciones y Costas)". Caso Duque vs. Colombia. 21 de noviembre de 2016, párr. 106. 〈http://www. corteidh.or.cr/docs/casos/articulos/seriec_310_esp.pdf>.

—. "Sentencia de 24 de febrero de 2012 (Excepciones Preliminares, Fondo, Reparaciones y Costas)". Caso Atala Riffo y niñas vs. Chile. 24 de febrero de 2012, párr. 90. 〈http://www. corteidh.or.cr/docs/casos/articulos/seriec_239_esp.pdf). 
—. "Sentencia de 27 de abril de 2012 (Excepciones Preliminares, Fondo, Reparaciones y Costas)". Caso Forenon e hija vs. Argentina. 27 de abril de 2012. 〈http://corteidh.or.cr/docs/ casos/articulos/seriec_242_esp.pdf〉.

—. "Sentencia de 31 de agosto de 2016 (Excepciones Preliminares, Fondo, Reparaciones y Costas)". Caso Flor Freire vs. Ecuador. 31 de agosto de 2016, párr. 106. 〈http://www. corteidh.or.cr/docs/casos/articulos/seriec_315_esp.pdf>.

Diez Picazo, Luis. Sistema de derechos fundamentales. Madrid: Civitas, 2008.

Ecuador. Constitución de la República del Ecuador. Registro Oficial 449, 20 de octubre de 2008, art. 11.2.

Ecuador Corte Constitucional. "Sentencia (matrimonio igualitario)". En Juicio n. ${ }^{o} 111-18$ CN/19 junio-CC, 12 de junio de 2019.

—. "Sentencia". En Juicio n. ${ }^{\circ}$ 184-18 Sep.-CC, 29 de mayo de 2018.

Eichler, Margrit. "Cambios familiares: del modelo patriarcal al modelo de responsabilidad individual en la familia". En El género en el derecho. Ensayos crítico, compilado por Ramiro Ávila, Judith Salgado y Lola Valladares. Quito: Ministerio de Justicia y Derechos Humanos, 2009.

Espinoza, Beatriz, ed. Cuerpos y diversidad sexual: aportes para la igualdad y el reconocimiento. Bogotá: Pontificia Universidad Javeriana, 2008.

FDI. Guía sobre la Opinión Consultiva OC-24/2017 de la Corte IDH: sobre la identidad de género, igualdad y no discriminación a parejas del mismo sexo y sus implicaciones jurídicas. San José: FDI, 2018.

Huaita Alegre, Marcela. Declaración Universal de Derechos Humanos: Texto y comentarios inusuales. San José: ILANUD, 2001.

Levi Strauss, Claude. Polémica sobre el origen y la universalidad de la familia. Barcelona: Anagrama, 1995.

Nuevo, Pablo. Reflexiones Constitucionales a propósito del llamado "Matrimonio Homosexual". Barcelona: Universidad Abat Oliva, 2006.

Oliva Gómez, Eduardo, Guardiola Villa y Judith Vera. "Hacia un concepto interdisciplinario de la familia en la globalización". Justicia Juris 10, n. ${ }^{\circ} 1$ (2014): 11-20.

ONU Asamblea General. Declaración Universal de Derechos Humanos. 10 de diciembre de 1948. núm. 217 A(III).

Ortega Ruiz, Pedro, y Ramón Mínguez Vallejo. "Familia y transmisión de valores". Teoría de la Educación 15 (2004): 33-56. «doi.org/10.14201/ted.3022〉.

Roa, Jorge Ernesto. La función consultiva de la Corte Interamericana. Bogotá: Universidad Externado de Colombia, 2015.

Rodríguez, Rafael. "La protección del derecho a la identidad de género de las personas trans en el ordenamiento jurídico peruano desde una mirada dialógica entre el Derecho Constitucional y el Derecho Internacional de los Derechos Humanos: avances, retrocesos y desafíos (2014-2018)". Revista del Instituto de la familia, n. ${ }^{\circ} 7$ (2018): 165-87. 
Vaggione, Juan Marco. "Las familias más allá de la heteronormatividad". En La Mirada de los jueces. Sexualidades diversas en la jurisprudencia latinoamericana, editado por Cristina Motta y Macarena Sáez. Bogotá: Red Alas, 2008.

Vieco, Luis Eduardo. "La universalización de los derechos humanos". Analecta Política, n. ${ }^{\circ}$ 3 (2012): 165-79.

Villabela, Carlos Manuel. "Constitución y democracia en el nuevo constitucionalismo latinoamericano". Revista del Instituto de Ciencias Jurídicas de Puebla, 25 (2010): 49-76.

Zagrebelsky, Gustavo. El derecho dúctil. Ley, derechos, justicia. Madrid: Trotta, 1997. 